\title{
Unemployment, mortality and the problem of health- related selection: Evidence from the Scottish and England \& Wales (ONS) Longitudinal Studies
}

Tom Clemens, Paul Boyle and Frank Popham

Longitudinal Studies Centre - Scotland (LSCS), University of St Andrews

Testing whether unemployment causes health deterioration is complicated because failing health may increase the probability of unemployment. In some previous studies of unemployment and mortality a 'wear-off' period is used to exclude any deaths occurring in the first few years after employment status was observed. It is assumed that selection effects will wear-off during this period. In this article the effectiveness of using wear-off periods is tested. Using data from the Scottish Longitudinal Study and the England and Wales Longitudinal Study, logistic regression models were used for estimating the odds of death in a given time period after the 1991 Census for those aged 35-64 in 1991. The odds ratios for the different economic positions (in work, unemployed, retired, permanently sick and other inactive) were compared, as well as the changes in risk associated with cumulatively increasing the length of wear-off prior to follow-up. No evidence was found of healthrelated selection for the unemployed in 1991. This observation was consistent across both studies. This suggests that the use of the five year wear-off period in many studies of mortality and unemployment may be an ineffective and unnecessary technique for mitigating the effects of health-related selection.

\section{Introduction}

The potential for unemployment to negatively affect an individual's health status has been the focus of much research. ${ }^{1}$ Associations between a spectrum of health outcomes and unemployment have been empirically borne out in the literature including mental health, ${ }^{2,3}$ substance use and teenage pregnancy, ${ }^{4}$ suicidal behaviours ${ }^{5}$ and limiting long-term illness (LLTI). ${ }^{6}$ In addition to these outcomes much work has sought to investigate associations between unemployment and mortality. $7,8,9,10,11,12,13$

While many of these studies report statistically strong associations between unemployment and poor health, establishing this as a causal relationship poses a greater challenge as they rely on observational rather than experimental studies. ${ }^{14,15}$ One problem stems from the possibility that health may be both an outcome of, and a cause of, unemployment; ill members of the population are at higher risk of unemployment so any observational analysis could exaggerate the direct effect of unemployment on health or mortality. ${ }^{16,17}$ If such health selection takes place, even strong relationships between unemployment and health cannot be regarded as causal. More generally, of course, there may be other (unobserved) factors that increase the likelihood of unemployment and therefore could potentially bias any claims that unemployment per se can increase the risk of subsequent poor health and death.

A number of techniques have been applied in attempts to overcome such selection issues. Commonly, longitudinal data are used and the various approaches include controlling for baseline health, ${ }^{18,19}$ studying whether the impact of unemployment differs at times of low and high overall unemployment when selection effects might be expected to vary, ${ }^{20,21,22}$ and studying the impact of unemployment experimentally when whole workforces are made, or threatened with being made redundant. ${ }^{23,24}$ 
Another common approach, based on the work of Fox et al, ${ }^{9}$ is to exclude deaths in the first few years of follow-up after employment status was observed. If the relative mortality risk is lowered when these deaths are excluded this suggests that health selection may have introduced bias which could result in an exaggeration of the effect of unemployment on mortality risk. As Bartley ${ }^{25}$ comments:

in a cohort study, any group selected for physical illness should exhibit high mortality in the early years of follow up which returns towards the level of the rest of the cohort later on as those who are very ill die and the rest recover.

There are reasons to suppose that this approach may not be as appropriate nowadays. In the UK, there has been a steady increase in those of working age who are permanently sick with some evidence suggesting that many of those who may previously have identified themselves as unemployed have been diverted to sickness related benefits. ${ }^{26}$ This may be typical of those with a limiting long-term illness (LLTI). ${ }^{27}$

A consequence of this is that by the time of the 1991 Census those classifying themselves as unemployed may be less likely to have done so because of poor health than may have been the case in the 1970s or 1980 s when studies such as those by Fox et $a l^{9}$ were conducted. Also, the addition of a question on work related LLTI in the 1991 UK Census provides the opportunity to control for health selection in a way that was not possible in previous UK census-based studies. This measure of health has demonstrated links to worklessness with evidence to suggest that unemployment independently increases an individual's chance of suffering a LLTI. ${ }^{28}$ Therefore, this study will utilise the LLTI measure to adjust for underlying baseline health which may cause confounding in the relationship between unemployment and mortality.

In this study, the Scottish Longitudinal Study (SLS) and the England and Wales ONS Longitudinal Study (ONS LS) are used to explore possible health-related selection into unemployment using post-1991 mortality data linked to individuals whose economic position was recorded in the 1991 Census. The association of unemployment with mortality is assessed by varying the length of the period during which mortality events are ignored and adjusting for limiting illness, recorded in 1991.

\section{Methods}

\section{Data and outcome variables}

The data for Scotland were extracted from the SLS which links census records from 1991 and 2001 for 5.3 per cent of the Scottish population. In addition, corresponding vital events registry data, from which mortality data are drawn, is also linked for this period and beyond up to 2003 (the last year for which mortality data had been recorded at the time this study was undertaken).The data for England and Wales were extracted from the ONS LS. The ONS LS links decennial census information for 1 per cent of the population in England and Wales from 1971, along with their registration data. Information from the 1971, 1981, 1991 and 2001 Censuses is linked with vital events information (births, deaths and cancer registrations), from which mortality data are drawn.

These longitudinal studies are dynamic samples; some members are lost to the study through emigration (moving to another country and settling), and death, and new members enter the study through birth and immigration. ${ }^{28,29}$ Sample selection is based on birth dates, using twenty dates in Scotland and four dates in England and Wales to create samples which are representative of the population.

The analysis focused on the working ages 35 to 64 which gave a sample size of 95,963 in the SLS and 193,712 in the ONS LS. A follow-up approach was employed in which economic position and the other socio-demographic information is recorded at the 1991 Census (21 April 1991) and then related to deaths occurring after the census. These mortality events are arranged, as detailed in Table 1, into periods of follow-up of various lengths with eight variables in total corresponding to eight varying periods during which mortality events are ignored prior to follow-up. The first of these periods of followup involved 0 months of wear-off, and thus contained all deaths that occurred within five years of the census (1991-95). The second period delayed mortality follow-up to the end of 1991 and thus ignored all deaths occurring eight months after the census but captured all mortality events in the subsequent five years (1992-96). The third period delayed mortality follow-up to the end of 1992 (20 months) and then captured mortality events in 1993-97. The remaining periods were produced following the same procedure up to period eight which involved delaying mortality follow-up by seven years and captured those deaths between 1998 and 2002. It was decided to carry out five-year follow-up analyses, rather than 10-year, to allow the maximum number of mortality wear-off periods which also allowed this period to be extended two years beyond the traditional five-year period that is often used while still allowing a substantial follow-up period.

\section{Table 1}

Length of wear-off period, mortality periods and mortality frequencies for each wear-off period

\begin{tabular}{|c|c|c|c|}
\hline \multirow[t]{2}{*}{ Length of wear-off period (Dates in brackets) } & \multirow{2}{*}{$\begin{array}{l}\text { Mortality } \\
\text { periods }\end{array}$} & \multicolumn{2}{|c|}{ Number of deaths } \\
\hline & & Scotland & $\begin{array}{c}\text { England } \\
\text { and Wales }\end{array}$ \\
\hline 0 Months & 1991-95 & 3,059 & 5,429 \\
\hline 8 Months $(21 / 04 / 91-31 / 12 / 91)$ & 1992-96 & 3,517 & 5,835 \\
\hline 20 Months (21/04/91-31/12/92) & 1993-97 & 3,760 & 6,208 \\
\hline 32 Months (21/04/91-31/12/93) & 1994-98 & 4,075 & 6,633 \\
\hline 44 Months (21/04/91-31/12/94) & 1995-99 & 4,284 & 7,096 \\
\hline 56 Months (21/04/91-31/12/95) & 1996-2000 & 4,442 & 7,528 \\
\hline 68 Months (21/04/91-31/12/96) & 1997-2001 & 3,966 & 7,954 \\
\hline 80 Months (21/04/91-31/12/97) & 1998-2002 & 3,146 & 8,392 \\
\hline
\end{tabular}

Source: Scottish Longitudinal Study; England and Wales ONS Longitudinal Study

\section{Analysis}

As the outcome was binary (whether the individual died or not in the period), binomial logistic regression models were used for each of the different length periods of follow-up beginning with 0 years through to 7 years successively (Box One provides a brief explanation of logistic regression). Two sets of two models were produced; a first set without direct control for LLTI and a second including this direct control. Within each set a base model including only age, age squared and sex was produced followed by a more complex full model including additional confounding variables drawn from the 1991 Census. The confounding variables were chosen on the basis of known associations with mortality and economic position and included age, age squared, sex, social class, marital status, educational attainment (1991), area deprivation quintile, and ethnicity. This additional adjustment ensured that the estimate of the association of unemployment with mortality was robust to these observed social factors. Odds ratios associated with the different categories of economic position were then graphed to see patterns of change with different length periods of follow-up. If health-related influences on the movement into unemployment were an issue which could be properly addressed using a wear-off period, the odds of unemployment-related mortality would be expected to be higher in the initial period immediately after 1991 and lower in the later mortality periods, when selection effects would be expected to have diminished. ${ }^{9}$ 


\begin{tabular}{|c|c|c|c|c|c|c|c|c|}
\hline \multirow[t]{2}{*}{ Variable } & \multicolumn{4}{|c|}{ Scotland } & \multicolumn{4}{|c|}{ England and Wales } \\
\hline & Frequency & Per cent & Deaths & Per cent ${ }^{1}$ & Frequency & Per cent & Deaths & Per cent ${ }^{1}$ \\
\hline \multicolumn{9}{|l|}{ Economic position } \\
\hline In work & 62,856 & 65.5 & 6,003 & 9.6 & 132,252 & 68.3 & 11,384 & 8.6 \\
\hline Unemployed & 5,600 & 5.8 & 1,213 & 21.7 & 10,841 & 5.6 & 1,802 & 16.6 \\
\hline Retired & 6,487 & 6.8 & 2,195 & 33.8 & 13,104 & 6.8 & 3,826 & 29.2 \\
\hline Permanently sick & 8,726 & 9.1 & 3,346 & 38.3 & 12,705 & 6.8 & 4,668 & 36.7 \\
\hline Other inactive & 12,294 & 12.8 & 1,610 & 13.1 & 24,810 & 12.8 & 2,591 & 10.4 \\
\hline \multicolumn{9}{|l|}{ Sex } \\
\hline Male & 46,747 & 48.7 & 8,237 & 17.6 & 96,522 & 49.8 & 14,390 & 14.9 \\
\hline Female & 49,216 & 51.3 & 6,130 & 12.5 & 97,190 & 50.1 & 9,881 & 10.2 \\
\hline \multicolumn{9}{|l|}{ Social class } \\
\hline Professional occupations & 3,218 & 3.4 & 266 & 8.3 & 7,374 & 3.8 & 604 & 8.2 \\
\hline Managerial and technical occupations & 22,331 & 23.3 & 2,070 & 9.3 & 48,496 & 25.0 & 4,153 & 8.6 \\
\hline Skilled non-manual occupations & 15,961 & 16.6 & 1,597 & 10.0 & 34,377 & 17.8 & 2,980 & 8.7 \\
\hline Skilled manual occupations & 17,179 & 17.9 & 2,774 & 16.1 & 34,501 & 17.8 & 4,751 & 13.8 \\
\hline Partly skilled occupations & 12,599 & 13.1 & 2,016 & 16.0 & 26,461 & 13.7 & 3,604 & 13.6 \\
\hline Unskilled occupations & 7,413 & 7.7 & 1,310 & 17.7 & 11,579 & 5.9 & 1,749 & 15.1 \\
\hline Armed forces & 259 & 0.3 & 14 & 5.4 & 517 & 0.3 & 31 & 6.0 \\
\hline No job in last ten years/not stated & 17,003 & 17.7 & 4,320 & 25.4 & 30,407 & 15.7 & 6,399 & 21.0 \\
\hline \multicolumn{9}{|l|}{ Marital status } \\
\hline Single & 8,639 & 9.0 & 1,733 & 20.1 & 15,766 & 8.1 & 2,635 & 16.7 \\
\hline Married (first marriage) & 68,395 & 71.3 & 9,064 & 13.3 & 131,478 & 67.9 & 14,818 & 11.3 \\
\hline Remarried & 7,350 & 7.7 & 962 & 13.1 & 21,159 & 10.9 & 2,446 & 11.6 \\
\hline Divorced & 7,095 & 7.4 & 1,268 & 17.9 & 17,948 & 9.3 & 2,528 & 14.1 \\
\hline Widowed & 4,484 & 4.7 & 1,340 & 29.9 & 7,361 & 3.8 & 1,844 & 25.1 \\
\hline \multicolumn{9}{|l|}{ Carstairs quintiles } \\
\hline One (least deprived) & 19,116 & 19.9 & 1,736 & 9.1 & 31,001 & 16.0 & 2,889 & 9.3 \\
\hline Two & 24,442 & 25.5 & 2,977 & 12.2 & 35,001 & 18.1 & 3,688 & 10.5 \\
\hline Three & 20,187 & 21.1 & 3,068 & 15.2 & 37,065 & 19.1 & 4,269 & 11.5 \\
\hline Four & 17,030 & 17.8 & 3,140 & 18.4 & 42,752 & 22.1 & 5,643 & 13.2 \\
\hline Five (most deprived) & 15,087 & 15.7 & 3,427 & 22.7 & 47,884 & 24.7 & 7,781 & 16.2 \\
\hline \multicolumn{9}{|l|}{ Ethnicity ${ }^{2}$} \\
\hline White & 95,115 & 99.1 & 14,309 & 15.0 & 181,442 & 93.7 & 23,121 & 12.7 \\
\hline Non-white & 848 & 0.9 & 58 & 6.8 & 12,270 & 6.3 & 1,085 & 8.8 \\
\hline \multicolumn{9}{|l|}{ Limiting long-term illness } \\
\hline Has a health problem & 14,885 & 15.5 & 5,229 & 35.1 & 25,996 & 13.4 & 8,283 & 31.9 \\
\hline Does not have a health problem & 81,078 & 84.5 & 9,138 & 11.3 & 167,716 & 86.6 & 15,988 & 9.5 \\
\hline
\end{tabular}

1 Death percentages are expressed as a proportion of deaths against all members in that group.

2 To allow comparison with Scotland, ethnicity figures for England and Wales are shown in reduced binary form. In the logistic regression analysis a longer form of the ethnicity variable was used when modelling the England and Wales data due to its larger sample size (see Appendix Table A1).

Source: Scottish Longitudinal Study; England and Wales ONS Longitudinal Study

\section{Box one}

\section{Logistic regression modelling}

A logistic regression model was used to model the probability of an LS member dying in the follow-up period. In a logistic regression the parameter estimates are known as logit coefficients. Logit coefficients can be used to construct prediction equations and generate predicted values. Logit coefficients represent changes in the log-odds of the dependent variable not the changes themselves, as is the case with Ordinary Least Squares regression. The most common way to interpret a logit is to convert it to an odds ratio using the exponential transformation. The odds ratio is easier to interpret, for example, in a logistic regression of the event dying $(0=$ not died, $1=$ died) on gender ( $0=$ female, $1=$ male), the logit coefficient is equal to 0.47 and the odds ratio is equal to 1.60 . This means that the odds of a male dying are 1.6 times higher than those for a female.

\section{Results}

Figures 1 and 2 present the results from the analysis. In almost all of the graphs, and in line with previous studies, being out of work for whatever reason is associated with an increased risk of death relative to those in work. The set one models in Figure 1 show that the unemployed are around two times more likely to die relative to those in work. Importantly, however, this relationship remains stable irrespective of the duration of follow-up in which mortality is ignored. However, for the permanently sick in the set one models in Figure 1, there is a marked selection pattern, with higher relative mortality risk in the earlier periods shortly after the census followed by a steady decline with increased duration of the mortality wear-off period.

The addition of the social class, marital status, area deprivation and ethnicity variables in the set two models in Figure 1 slightly attenuated the relationship between all out of work categories and mortality (compared with the 'in work') but the relative relationships remained 

given wear-off period. Set one models are adjusted for age, age (squared) and sex. Set two models are additionally adjusted for social class, marital status, deprivation and ethnicity

\section{Scotland}
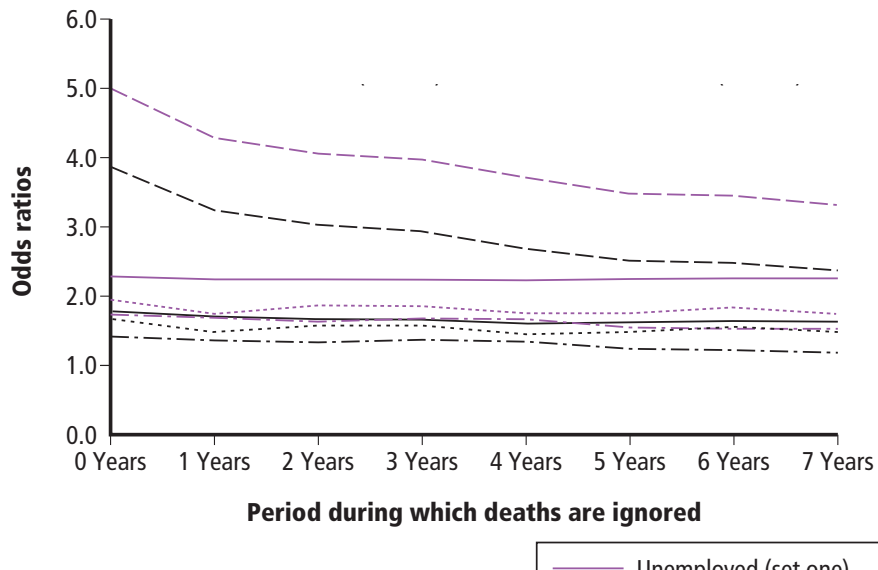

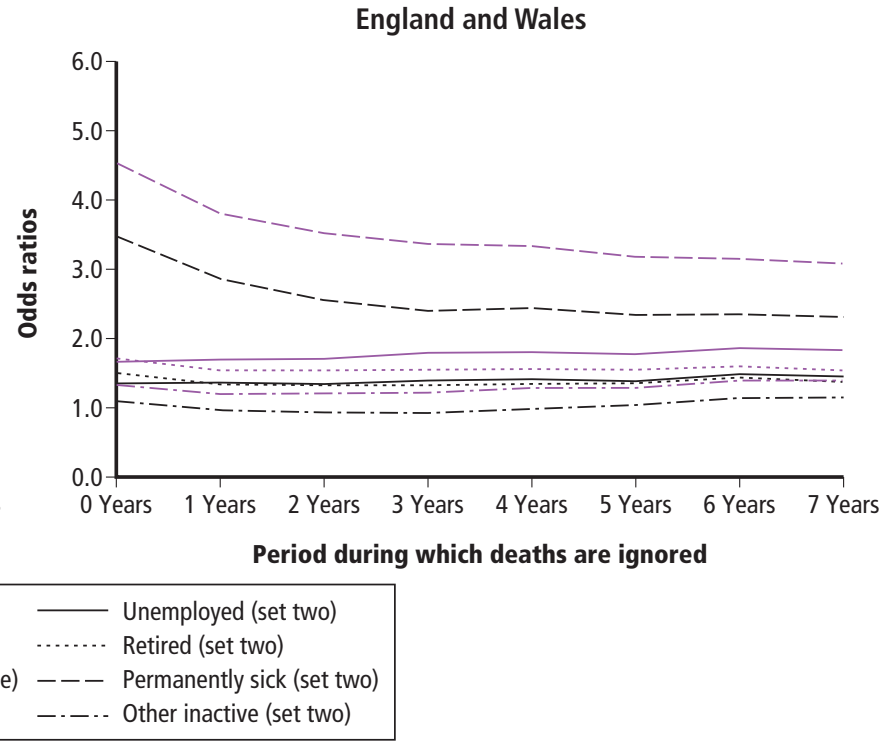

England and Wales

Source: Scottish Longitudinal Study; England and Wales ONS Longitudinal Study

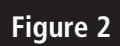

Odds ratios for levels of economic position from two sets of eight logistic regression models predicting mortality within a given wear-off period. Set one models are adjusted for age, age (squared), sex and limiting long-term illness. Set two models are additionally adjusted for social class, marital status, deprivation and ethnicity

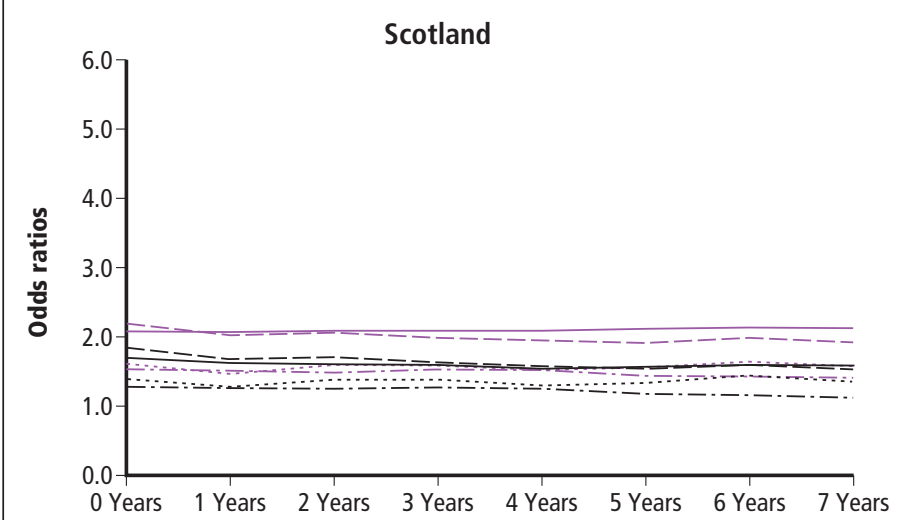

Period during which deaths are ignored

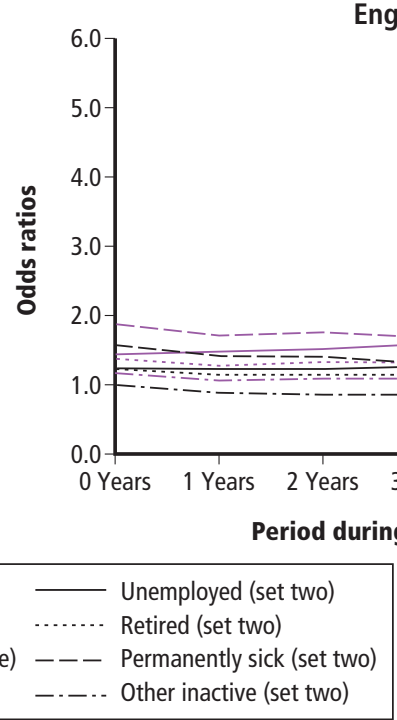

England and Wales

\begin{tabular}{|c|c|}
\hline Unemployed (set one) & — Unemployed (set two) \\
\hline Retired (set one) & Retired (set two) \\
\hline - - Permanently sick (set one) & --- Permanently sick (set two) \\
\hline --_-. Other inactive (set one) & ----- Other inactive (set two) \\
\hline
\end{tabular}

Source: Scottish Longitudinal Study; England and Wales ONS Longitudinal Study

unchanged for unemployment and permanent sickness. The relationship between unemployment and mortality remained stable irrespective of the duration of the mortality wear-off period that is used despite this additional adjustment for social factors.

Controlling for LLTI in the set one models in Figure 2 attenuates the relationship for the unemployed but the relative pattern remains the same, with the mortality risk for the unemployed unchanged by the duration of mortality wear-off. The selection shape for the permanently sick that is apparent in Figure 1 disappears with the addition of LLTI as a control variable. This has the effect of removing the excess risk of death for the permanently sick to the point that it closely matches the risk magnitude of the unemployed, a relationship that is mostly constant across all of the different periods of follow-up. This relationship holds when adjusted for the other social factors as well as LLTI in the set two models in Figure 2. (Appendix Table A1 shows the full model output with adjustment for LLTI and other social factors including odds ratios and significance tests for the zero wear-off period and 80 months wear-off period for both England and Wales and Scotland.) 


\section{Discussion}

In line with almost all work completed previously in this field, being unemployed is related to significantly higher odds of death relative to being employed in all of the models. This relationship is apparent both generally and after adjustment for individual socio-economic circumstances.

However, as described above, drawing causal conclusions about this relationship has been complicated by the potential for ill health to influence employment status. Thus, the strong associations between unemployment and mortality may reflect a concentration of unhealthy members of the population within the unemployed group rather than a causal effect of unemployment on health per se. A popular technique in prospective studies has been to allow these potential selection effects to diminish by ignoring all mortality events that occurred within the first five years after economic position is observed. As Fox et $a l^{9}$ suggest, this period allows for non-steady state unemployed individuals to either recover and return to the labour force or die.

This analysis therefore explored whether it was possible to detect a change in the odds of death of the unemployed relative to the employed depending upon the length of this delayed mortality follow-up period. The analysis was interested in both the effectiveness of this technique as well as potentially illustrating the effect and magnitude of these selection effects. Assuming that this delayed mortality follow-up approach is appropriate, the evidence presented above suggests that the process of selection into unemployment of sick individuals is non-existent. If strong selection effects were present, the unemployed group might be expected to experience higher likelihoods of death initially with this figure declining steadily over time until reaching a steady state around the five year delayed mortality follow-up period. Indeed the distribution might be expected, at a lower magnitude, to match more closely the pattern exhibited by the permanently sick category in which a steady decline in the likelihood of death is seen as those suffering acute illness either die or recover. This was not the case. Furthermore, direct adjustment for LLTI had the effect of drastically reducing the apparent effects of selection in the permanently sick. However, it is important to note that nearly all individuals who are registered permanently sick in the census are also coded as having a LLTI which may complicate this conclusion.

While literature on social class inequalities in mortality appears to show the presence of health selection effects when both the unemployed and permanently sick are included, ${ }^{31,32,33}$ the lack of selection effects in the results for the unemployed seems to accord with some suggestions made in the unemployment literature previously, although these do not appear to have been rigorously tested. For example, Moser et $a l^{10}$ used a 'wear-off' period following the 1971 England and Wales Census and suggested that the overall mortality risk associated with unemployment was little changed by excluding deaths in the initial years. Bartley's review of unemployment and mortality studies, mainly conducted using 1971 and 1981 Census data, concludes, 'this [wear-off] pattern is seen in men who are permanently sick but not in the unemployed. 25

These results, particularly the apparent lack of any selection processes among the unemployed, leave two possible explanations. First, the sample of individuals (aged 35-64) may include a majority of steadystate employment status experiences. For example, it is plausible that a significant majority of the group of unemployed had been unemployed for at least five years (prior to 1991) thus removing the potential for them to be unemployed through ill health in this period. In this analysis, the unemployed maintained constant higher odds ratios relative to the employed group. This explanation was suggested as a possible reason accounting for the lack of apparent selection effects found in the work of Fox et al. ${ }^{9}$ However, it seems highly improbable that a majority of the unemployed group would have been in this steady state of unemployment for the requisite length of time to mask the effects of selection.
A second explanation could be simply that the role or magnitude of any selection effects for unemployment status and health are minimal in this sample. The odds ratios for the unemployed, while being significantly higher relative to the employed, remained mostly constant suggesting that unemployed individuals are dying at the same rates regardless of the duration of the period in which deaths were ignored. In the literature to date, a delay of five years when following up mortality events has been widely adopted as it is deemed an appropriate timescale for unemployment to have had an impact on a person's health if one were to exist. This allows for those individuals who became unemployed due to poor health to either die or recover and allows the researcher to begin to rule out the possibility of health selection. However, if the unemployed group had contained a significant number of recently unemployed individuals due to ill health, the patterns described by Fox and colleagues of an early peak in odds ratios followed by gradual decline would be expected to be seen.

Finally, it is worth mentioning the findings of Martikainen $e a^{20}$ which suggest that the association between unemployment and health may differ during periods of higher and lower general levels of population wide unemployment figures. The timing of the 1991 Census coincided with a period of economic slowdown which could potentially result, according to Martikainen et al, in a period when the health effects of unemployment may have been masked. This would appear to suggest that, if anything, the analysis has underestimated the true strength of the relationship between unemployment and health.

In conclusion this study has found little evidence of a selection effect operating on the unemployed within the 1991 Census measure of economic position. The technique of delaying follow-up of mortality events for five years following measurement of economic position may be an unnecessary and ineffective method for mitigating the effects of health-related selection for the unemployed.

\section{Acknowledgements}

The help provided by staff of the Longitudinal Studies Centre - Scotland (LSCS) is acknowledged. The LSCS is supported by the Economic and Social Research Council (ESRC)/Joint Information Systems Committee, the Scottish Funding Council, the Chief Scientist's Office and the Scottish Executive. The authors alone are responsible for the interpretation of the data

Census output is Crown copyright and is reproduced with the permission of the Controller of HMSO and the Queen's Printer for Scotland.

Special thanks to Shayla Goldring and Kevin Lynch at the Office for National Statistics for replicating the original Scottish analysis in England and Wales using data from the ONS Longitudinal Study.

The authors would like to recognise the help and support of members of the Transitions, choices and health at older ages: life course analyses of longitudinal data project. (ESRC Grant reference: RES-352-25-0015).

This study was completed with funding from the ESRC for Tom Clemens' PhD.

\section{References}

1. Bartley M, Ferrie J and Montgomery S M (2006) 'Health and labour market disadvantage: unemployment, non-employment, and job insecurity', Social Determinants of Health 2nd edition, Oxford University Press: Oxford, 78.

2. Nordenmark M and Strandh M (1999) 'Towards a sociological understanding of mental well-being among the unemployed: the role of economic and psychosocial factors', Sociology 33(3), 577-97. 
3. Thomas C, Benzeval M and Stansfeld S A (2005) 'Employment transitions and mental health: an analysis from the British household panel survey', Journal of Epidemiology and Community Health 59(3), 243-49.

4. Fergusson D M, Horwood L J and Woodward L J (2001) 'Unemployment and psychosocial adjustment in young adults: causation or selection?' Social Science \& Medicine (1982) 53(3), 305-20.

5. Blakely T A, Collings S C and Atkinson J (2003), 'Unemployment and suicide. Evidence for a causal association?' Journal of Epidemiology and Community Health 57(8), 594-600.

6. Bartley M, Sacker A and Clarke P (2004) 'Employment status, employment conditions, and limiting illness: prospective evidence from the British household panel survey 1991-2001', Journal of Epidemiology and Community Health 58(6), 501-06.

7. Morrell S, Taylor R, Quine S et al (1999) 'A case-control study of employment status and mortality in a cohort of Australian youth', Social Science \& Medicine 49(3), 383-92.

8. Moser K, Goldblatt P and Fox A (1987) 'Unemployment and mortality, 1981-3: follow-up of the 1981 Census sample', British Medical Journal 294, 86-90.

9. Fox A J, Goldblatt, P O and Adelstein A M (1982) 'Selection and mortality differentials', Journal of Epidemiology and Community Health 36(2), 69-79.

10. Moser K A, Fox A J and Jones D R (1984) 'Unemployment and mortality in the OPCS Longitudinal Study', The Lancet 324(8415), 1324-329.

11. Voss M, Nylén L, Floderus B et al (2004) 'Unemployment and Early Cause-Specific Mortality: A Study Based on the Swedish Twin Registry', American Journal of Public Health 94(12), 2151-161.

12. Stefansson C G (1991) 'Long-term unemployment and mortality in Sweden, 1980-1986', Social Science \& Medicine 32(4), 419-23.

13. Gerdtham U G and Johannesson M (2003) 'A note on the effect of unemployment on mortality', Journal of Health Economics 22, 505-18.

14. Rubin D (2008) 'For objective causal inference, design trumps analysis', The Annals of Applied Statistics 2(3), 808-40.

15. Oswald A J (2007) 'Commentary: Human well-being and causality in social epidemiology', International Journal of Epidemiology 36(6), 1253-254.

16. Bartley M and Ferrie J (2001) 'Glossary: unemployment, job insecurity, and health', Journal of Epidemiology and Community Health 55(11), 776-81.

17. Bartley M (1996) 'Unemployment and health selection', The Lancet 348(9032), 909-12.

18. Martikainen P T (1990) 'Unemployment and mortality among Finnish men, 1981-5', British Medical Journal 301(6749), 407-11.

19. Montgomery S M, Cook D G, Bartley M J and Wadsworth M E (1999) 'Unemployment pre-dates symptoms of depression and anxiety resulting in medical consultation in young men', International Journal of Epidemiology 28(1), 95-100.

20. Martikainen P and Valkonen T (1996) 'Excess mortality of unemployed men and women during a period of rapidly increasing unemployment', The Lancet 348(9032), 909-12.

21. Martikainen P and Valkonen T (1998) 'The effects of differential unemployment rate increases of occupation groups on changes in mortality', American Journal of public health 88, 1859-861.
22. Martikainen P, Mak N and Jantti M (2007) 'The effects of unemployment on mortality following workplace downsizing and workplace closure: A register-based follow-up study of Finnish men and women during economic boom and recession', American Journal of Epidemiology 165(9), 1070-75.

23. Ferrie J E, Martikainen P, Shipley M J et al (2001) 'Employment status and health after privatisation in white collar civil servants: prospective cohort study', British Medical Journal 322(7287), 647-54.

24. Steenland K and Pinkerton L E (2008) 'Mortality patterns following downsizing at Pan American World Airways', American Journal of Epidemiology 167(1), 1-6.

25. Bartley M (1994) 'Unemployment and ill health: understanding the relationship', Journal of Epidemiology and Community Health $\mathbf{4 8 ,}$ 333-37.

26. Beatty $\mathrm{C}$ and Fothergill $\mathrm{S}$ (2005) 'The diversion from 'unemployment' to 'sickness' across British regions and districts' Regional Studies: The Journal of the Regional Studies Association 39, 837-54.

27. Bartley M and Owen C (1996) 'Relation between socioeconomic status, employment and health during economic change 1973-93', British Medical Journal 313(7055), 445-49.

28. Bartley M and Plewis I (2002) 'Accumulated labour market disadvantage and limiting long-term illness: data from the 1971-1991 Office for National Statistics Longitudinal Study', International Journal of Epidemiology 31, 336-41

29. Hattersley L and Boyle P (2007) 'The Scottish Longitudinal Study: An Introduction', LSCS Working paper 1.0, Longitudinal Studies Centre Scotland: St Andrews.

30. Blackwell L, Lynch K, Smith J and Goldblatt P (2003) 'ONS Longitudinal Study 1971-2001: Completeness of Census Linkage', Series LS no.10, Office for National Statistics: London. Available on the Office for National Statistics website at: www.statistics.gov.uk/statbase/Product.asp?vlnk=10721

31. Exeter D, Boyle P, Feng Z and Flowerdew R (2005) 'Consistent areas through time (CATTS) in Scotland, 1981-2001', Population Trends 119, 28-36.

32. Donkin A, Goldblatt P and Lynch K (2002) 'Inequalities in life expectancy by social class 1972-1999', Health Statistics Quarterly 15, 5-15. Available on the Office for National Statistics website at: www.statistics.gov.uk/statbase/Product.asp?vlnk=6725

33. White C, Glickman M, Johnson B and Corbin T (2007) 'Social inequalities in adult male mortality by the National Statistics SocioEconomic Classification, England and Wales, 2001-03', Health Statistics Quarterly 36, 6-23. Available on the Office for National Statistics website at: www.statistics.gov.uk/statbase/Product.asp?vlnk $=6725$

34. White C, Wiggins R, Blane D et al (2005) 'Person place or time? The effect of individual circumstances, area and changes over time on mortality in men, 1995-2001', Health Statistics Quarterly 28, 18-26. Available on the Office for National Statistics website at: www.statistics.gov.uk/statbase/Product.asp?vlnk=6725 


\section{Appendix}

\section{Table A1}

Example model output with odds ratios and significance tests for models predicting death in zero wear-off period and seven-year wear-off period

\begin{tabular}{|c|c|c|c|c|c|}
\hline \multirow[b]{2}{*}{ Variable } & \multicolumn{2}{|c|}{$\begin{array}{l}\text { Model } \\
\text { Scotland }\end{array}$} & \multirow[b]{2}{*}{ Variable } & \multicolumn{2}{|c|}{$\begin{array}{c}\text { Model } \\
\text { England and Wales }\end{array}$} \\
\hline & Period 0 & Period 7 & & Period 0 & Period 7 \\
\hline Economic position & & & Economic position & & \\
\hline Unemployed & $1.687^{* * *}$ & $1.580^{* * *}$ & Unemployed & $1.231^{* * *}$ & $1.366^{* * *}$ \\
\hline Retired & $1.392^{* * *}$ & $1.350^{* * *}$ & Retired & $1.247^{* * *}$ & $1.234^{* * *}$ \\
\hline Permanently sick & $1.835^{* * *}$ & $1.533^{* * *}$ & Permanently sick & $1.598^{* * *}$ & $1.392^{* * *}$ \\
\hline Other inactive & $1.270^{* * *}$ & 1.124 & Other inactive & 0.992 & 1.076 \\
\hline Age & $1.131 * * *$ & $1.149^{* * *}$ & Age & $1.104^{* * *}$ & $1.110^{* * *}$ \\
\hline Age $^{1}$ & 1.000 & 1.000 & Age $^{1}$ & 1.000 & 1.000 \\
\hline Sex & & & Sex & & \\
\hline Male & $1.650^{* * *}$ & $1.704^{* * *}$ & Male & $1.616^{* * *}$ & $1.752^{* * *}$ \\
\hline Social class & & & Social class & & \\
\hline Managerial and technical occupations & 1.078 & 1.118 & Managerial and technical occupations & 0.915 & $1.245^{* * *}$ \\
\hline Skilled non-manual occupations & 1.157 & 1.136 & Skilled non-manual occupations & 1.014 & 1.420 *** \\
\hline Skilled manual occupations & 1.242 & 1.520 *** & Skilled manual occupations & 1.1 & $1.536^{* * *}$ \\
\hline Partly skilled occupations & 1.108 & $1.506^{* * *}$ & Partly skilled occupations & $1.188^{*}$ & $1.753^{* * *}$ \\
\hline Unskilled occupations & 1.233 & $1.693^{* * *}$ & Unskilled occupations & 1.17 & $1.828^{* * *}$ \\
\hline Armed forces & 0.802 & 0.911 & Armed forces & 1.12 & $1.301^{*}$ \\
\hline No job in last ten years/not stated & $1.503^{* * *}$ & $1.842^{* * *}$ & No job in last ten years/not stated & $1.419^{* * *}$ & $2.029 * * *$ \\
\hline Marital status & & & Marital status & & \\
\hline Married (first marriage) & $0.763^{* * *}$ & $0.726^{* * *}$ & Married (first marriage) & $1.481^{* * *}$ & 1.491 *** \\
\hline Remarried & $0.690^{* * *}$ & $0.768^{* * *}$ & Remarried & $1.157^{* * *}$ & 1.141 *** \\
\hline Divorced & 0.916 & 0.92 & Divorced & $1.329 * * *$ & $1.354^{* * *}$ \\
\hline Widowed & 1.06 & 0.99 & Widowed & $1.260^{* * *}$ & 1.401 *** \\
\hline Carstairs quintiles & & & Carstairs quintiles & & \\
\hline Two & 1.054 & $1.211 * * *$ & Two & 0.001 & $1.088^{*}$ \\
\hline Three & $1.154^{* *}$ & $1.243^{* * *}$ & Three & 0.954 & $1.150 * * *$ \\
\hline Four & $1.204^{* * *}$ & $1.417^{* * *}$ & Four & $1.044^{* *}$ & $1.258^{* * *}$ \\
\hline Five (most deprived) & $1.262^{* * *}$ & $1.534^{* * *}$ & Five (most deprived) & $1.123^{* * *}$ & $1.370^{* * *}$ \\
\hline Ethnicity2 & & & Ethnicity ${ }^{2}$ & & \\
\hline \multirow[t]{7}{*}{ Non-white } & 0.641 & $0.335^{* * *}$ & Black-Caribbean & $0.579^{* * *}$ & $0.565^{* * *}$ \\
\hline & & & Black-African & 0.901 & 0.686 \\
\hline & & & Indian & 0.791 ** & 0.780 *** \\
\hline & & & Pakistani & $0.644^{* * *}$ & $0.795^{*}$ \\
\hline & & & Bangladeshi & $0.451^{* * *}$ & $0.700^{*}$ \\
\hline & & & Chinese & 0.552 & 0.946 \\
\hline & & & Mixed or other & $0.522^{* * *}$ & $0.696^{* *}$ \\
\hline Limiting long-term illness & & & Limiting long-term illness & & \\
\hline Has a health problem & $2.336 * * *$ & $1.639 * * *$ & Has a health problem & $2.479 * * *$ & $1.770 * * *$ \\
\hline
\end{tabular}

1 Age (squared).

2 Due to the larger sample size in the England and Wales ONS Longitudinal Study a more detailed variable for ethnicity was used than was possible with the Scottish data.

${ }^{*} p<0.10$

** $p<0.05$

$* * * p<0.01$

Source: Scottish Longitudinal Study; England and Wales ONS Longitudinal Study 